\title{
Serum AChE Activities Predict Exercise Heart Rate Parameters of Asymptomatic Individuals
}

\author{
Jonathan Canaani ${ }^{1}$, Shani Shenhar-Tsarfaty ${ }^{1}$, Nir Weiskopf $^{2}$, Reut Yakobi ${ }^{1}$, Einor Ben Assayag, \\ Shlomo Berliner ${ }^{1}$, Hermona Soreq ${ }^{2 \ddagger}$
}

J. Canaani and S. Shenhar-Tsarfaty contributed equally to this work

${ }^{1}$ The Tel Aviv Sourasky Medical Center, Israel; ${ }^{2}$ The Life Sciences Institute, The Hebrew University, Jerusalem, Israel.

¥To whom correspondence should be addressed at the above address: Hermona Soreq, PhD, Biological Chemistry Department, The Hebrew University of Jerusalem, Givat Ram, Jerusalem, Israel.

Email: soreq@cc.huji.ac.il

Received August 21 ${ }^{\text {st }}, 2010$; revised September 15 ${ }^{\text {th }}, 2010$; accepted September $17^{\text {th }}, 2010$

\begin{abstract}
Background specific heart rate parameters notably associate with variable risks of cardiovascular disease and mortality, however, to date there are no readily available blood tests associated with these parameters. Because of the established parasympathetic contributions towards cardiac regulation, we challenged the working hypothesis that serum acetylcholinesterase (AChE) activity is involved. Methods A total of 403 Healthy men and women were included in the study and underwent treadmill exercise testing. Prior to exercise testing the subject's serum AChE activity levels were assessed by measuring rates of acetylthiocholine hydrolysis. Results In male subjects AChE activity was positively correlated to resting heart rate $(r=0.210, p=0.001)$. Complementing this observation, AChE activity was negatively correlated to the exercise-induced heart rate increase $(r=-0.181, p=0.005)$ and to heart rate recovery at 1,2 and 5 minutes following cessation of exercise ( $r=-0.150, p=0.022 ; r=-0.157, p=0.016 ; r=-0.176, p=0.008$ respectively). This indicated that lower than average AChE activities, which presumably reflect increased peripheral ACh levels, might be correlated to favorable heart rate parameters. Similar observations were made in female subjects, except for lack of correlation to their resting heart rate. Additionally, we observed that we were able to stratify subjects into two groups of significantly different AChE activity $(p=0.001)$ based on a cut point of heart rate recovery below 20 beats one minute after cessation of exercise. Conclusion In asymptomatic individuals lower than average AChE activity is associated with favorable indices of exercise-inducible heart rate increase as well as heart rate recovery. Future studies will be needed to evaluate the added prognostic significance gained by implementing this marker into routine practice.
\end{abstract}

Keywords: Exercise, Nervous System, Autonomic, Heart Rate

\section{Introduction}

A vast body of clinical and experimental evidence indicates that cardiovascular functioning is tightly linked to autonomous nervous system (ANS) activities. Prior studies have shown that autonomic imbalance, being either a decrease in vagal tone or an increase in sympathetic activity is associated with increased mortality due to cardiovascular pathologies including myocardial infarction [1,2] and cardiac arrhythmias [3]. Indirect measures of cardiac parasympathetic dysfunction obtained during exercise testing such as elevated resting heart rate, delayed heart rate recovery (HRR) from exercise and attenuated heart rate increase (HRI) during exercise have been shown to be independent predictors for adverse cardiovascular outcome [4-6].

The principal neurotransmitter of the parasympathetic branch of the ANS is acetylcholine (ACh), the levels of which are regulated by the enzyme acetylcholinesterase $(\mathrm{AChE})$ and the closely related butyrylcholinesterase (BChE), collectively determining the total cholinesterase activity [7]. Based on previous studies demonstrating the protective effect of ACh on ischemic myocardium [8,9] and that administration of pyridostigmine, an inhibitor of AChE, improved HRR and resting heart rate both in healthy subjects [10] and in heart failure patients [11], we sought to determine whether the peripheral serum levels of $\mathrm{AChE}$ and $\mathrm{BChE}$ (i.e. the total cholinesterase activity tested by aspecific assay [12]) can serve as biomarkers for assessing the aforementioned parameters of 
autonomic activity.

Specifically, we hypothesized that in apparently healthy individuals, increased serum levels of $\mathrm{AChE}$ and/or BChE, which presumably reflect lower peripheral ACh levels would be correlated with an abnormal heart rate profile including resting heart rate, heart rate increase during exercise and heart rate recovery after exercise.

\section{Methods}

\subsection{Study Population}

The study included 403 men and women who were recruited to the Tel Aviv Medical Center Inflammation Survey (TAMCIS) which comprises a population of apparently healthy individuals attending the Tel Aviv Sourasky Medical Center for routine health examinations [13,14]. Exclusion criteria included underlying inflammatory disease (arthritis, inflammatory bowel disease, etc.), as well as any infections or other inflammatory conditions such as myocardial infarction, surgery or angiography during the 6 months preceding study enrollment. Cancer patients were excluded as well. To minimize the effect of some important confounders, we excluded an additional 44 subjects based on their medication usage, including alpha and beta blockers and Amiodarone (owing to their chronotropic effects). All individuals included in the present study provided written consent according to the instructions of the Institutional Ethics Committee which approved this study (approval number 02-049).

\subsection{Clinical Data}

Prior to exercise testing, a review of each patient's chart and a structured interview were conducted to gather data on symptoms, medications, coronary risk factors, previous cardiac events, and other diagnoses. Hypertension was defined as a systolic blood pressure of $\geq 140 \mathrm{~mm} \mathrm{Hg}$ at rest, a diastolic blood pressure of $\geq 90 \mathrm{~mm} \mathrm{Hg}$ at rest in two separate measurements, or treatment with antihypertensive medication. Dyslipidemia was defined as low density lipoprotein (LDL) cholesterol concentration or non-high density lipoprotein (HDL) cholesterol concentrations, for individuals with triglyceride concentrations of $>200 \mathrm{mg} / \mathrm{dl}$, above the recommended number according to the risk profile defined by the updated ATP III recommendations [15] or the use of lipid-lowering medication.

\subsection{Exercise Test Protocol}

All subjects performed treadmill exercise testing using the standardized Bruce protocol [16]. The Quinton Q STRESS TM 55 (Quinton Instrument Company, Bothell, Washington) hardware and software were used for recording and analyz- ing stress test data. Heart rate was measured at rest, before exercise, and every two minutes during exercise, at peak exercise, and at one, two and five minutes during recovery. The heart-rate increase was defined as the difference between the peak exercise rate and the resting rate, and heart-rate recovery was defined as the reduction in rate from the peak exercise level to the rate one, two and five minutes following cessation of exercise. Exercise capacity was measured in watts, which were converted to maximum oxygen consumption calculated as metabolic equivalents (MET) [17].

\subsection{Enzyme Activity Measurements}

Blood was drawn in the morning (7:15-10:30 am) after a fasting period of at least 12 hours. Following centrifugation, serum samples were checked for lack of red blood cells contaminants and were then stored at $-80^{\circ} \mathrm{C}$ until cholinesterase activities were determined. AChE activity levels were assessed in a microtiter plate assay by measuring rates of acetylthiocholine (ATCh, Sigma, $1 \mathrm{mM}$ ) hydrolysis following $20 \mathrm{~min}$ pre-incubation in the dark, with 500 micromolar tetraisopropyl pyrophosphoramide (iso-OMPA, Sigma), a specific BChE inhibitor [18]. The non-enzymatic breakdown of substrate was subtracted from the total rate of hydrolysis. Enzyme activities were calculated using the e405 for 5-thio-2-nitrobenzoate, 13.600 $\mathrm{M} / \mathrm{cm}$ [19]. The total cholinesterase activity (combined activity of $\mathrm{AChE}$ and $\mathrm{BChE}$ ) was determined by measuring the rates of ATCh hydrolysis without a cholinesterase inhibitor [12]. All laboratory methods were performed by a blinded technician, each method by the same person for all measures. Several samples were routinely thawed and re-tested in subsequent days to evaluate between-days variability of measurements, which were found to be lower than $10 \%$, excluding batch effects.

\subsection{Statistical Analysis}

Collected data was summarized and displayed as mean \pm $\mathrm{SD}$, Continuous values with non-Gaussian distributions were compared by the Wilcoxon rank-sum or MannWhitney $\mathrm{U}$ test. The $\chi^{2}$ test was used to assess associations among categorical variables. Correlations between the cholinesterase activities and exercise test parameters were determined using the two-tailed Spearman rank correlation. Significance was set at $p<0.05$. Analyzing data with the One-Sample Kolmogorov-Smirnov test yielded a p-value of 0.001 , indicating that $\mathrm{AChE}$ activity did not distribute normally. SPSS/WIN (version 15.0, SPSS INC, Chicago, IL, USA) software was used to carry out all statistical analyses.

\section{Results}

Baseline clinical characteristics of study subjects are listed in Table 1. The study cohort consisted of 403 sub- 
jects, $65 \%$ of whom were male. Men tended to have slightly higher systolic and diastolic blood pressure. There was no significant gender difference in the rates of subjects with Diabetes mellitus, Dyslipidemia and active smoking. Parameters of the heart rate profile during exercise are shown in Table 2 .A gender difference is noted when examining most parameters. Women had higher basal heart rate prior to exercise but lower heart rate at the end of exercise compared to men. Women also showed lower exercise capacity but better heart rate recovery values 1,2 and 5 minutes following exercise. Both total

Table 1. Baseline characteristics of study participants according to gender.

\begin{tabular}{lccc}
\hline & $\begin{array}{c}\text { Men } \\
(\mathrm{n}=262)\end{array}$ & $\begin{array}{c}\text { Women } \\
(\mathrm{n}=141)\end{array}$ & $P$ \\
\hline $\begin{array}{l}\text { Characteristic } \\
\text { Age (years) }\end{array}$ & $45.1(10.6)$ & $46.7(9.8)$ & 0.123 \\
BMI (Kg/m2) & $27.0(3.8)$ & $26.2(5.2)$ & 0.101 \\
$\begin{array}{l}\text { Systolic blood pressure } \\
\text { (mm Hg) }\end{array}$ & $123.0(12.5)$ & $\begin{array}{c}116.0 \\
(12.9)\end{array}$ & $<0.001$ \\
$\begin{array}{l}\text { Diastolic blood pressure } \\
\text { (mm Hg) }\end{array}$ & $76.6(6.7)$ & $73.5(7.5)$ & $<0.001$ \\
& 33.6 & 20.6 & 0.006 \\
$\begin{array}{l}\text { Hypertension, \% } \\
\text { Diabetes mellitus, \% }\end{array}$ & 6.1 & 2.2 & 0.087 \\
& 18.6 & 15.2 & 0.397 \\
Dyslipidemia, \% & 17.8 & 20.4 & 0.527 \\
\hline
\end{tabular}

$B M I$ body mass index, Data are presented as mean \pm standard deviation.

cholinesterase activities and $\mathrm{AChE}$ activities were considerably lower in females compared to male subjects $(p<$ 0.001 for both $\mathrm{AChE}$ alone and $\mathrm{AChE}$ and $\mathrm{BChE}$ ), pre-

Table 2. Exercise test variables.

\begin{tabular}{lccc}
\hline \multicolumn{1}{c}{ Variable } & $\begin{array}{c}\text { Men } \\
(\mathrm{n}=262)\end{array}$ & $\begin{array}{c}\text { Women } \\
(\mathrm{n}=141)\end{array}$ & $P$ \\
\hline Basal heart rate (beat/min) & $69.3(11.4)$ & $72.7(11.3)$ & 0.004 \\
$\begin{array}{l}\text { Heart rate peak, (beat/min) } \\
\text { Heart rate } 1 \text { min after } \\
\text { end of exercise (beat/min) }\end{array}$ & $163.5(12.1)$ & $161.3(11.8)$ & 0.081 \\
$\begin{array}{l}\text { Heart rate 2 min after end } \\
\text { of exercise (beat/min) }\end{array}$ & $110.2(13.7)$ & $101.8(17.3)$ & $<0.001$ \\
$\begin{array}{l}\text { Heart rate } 5 \text { min after } \\
\text { end of exercise (beat/min) }\end{array}$ & $93.1(11.0)$ & $87.3(10.8)$ & $<0.001$ \\
$\begin{array}{l}\text { Heart rate recovery } \\
1 \text { min (beat/min) }\end{array}$ & $28.8(9.3)$ & $30.8(10.2)$ & 0.046 \\
$\begin{array}{l}\text { Heart rate recovery } \\
2 \text { min (beat/min) }\end{array}$ & $53.2(13.2)$ & $59.5(17.2)$ & $<0.001$ \\
$\begin{array}{l}\text { Heart rate recovery } \\
5 \text { min (beat/min) }\end{array}$ & $70.4(13.3)$ & $73.9(12.1)$ & 0.011 \\
Exercise capacity (MET) & $14.2(3.3)$ & $10.8(2.5)$ & $<0.001$ \\
\hline
\end{tabular}

MET metabolic equivalent, Data are presented as mean \pm standard deviation.

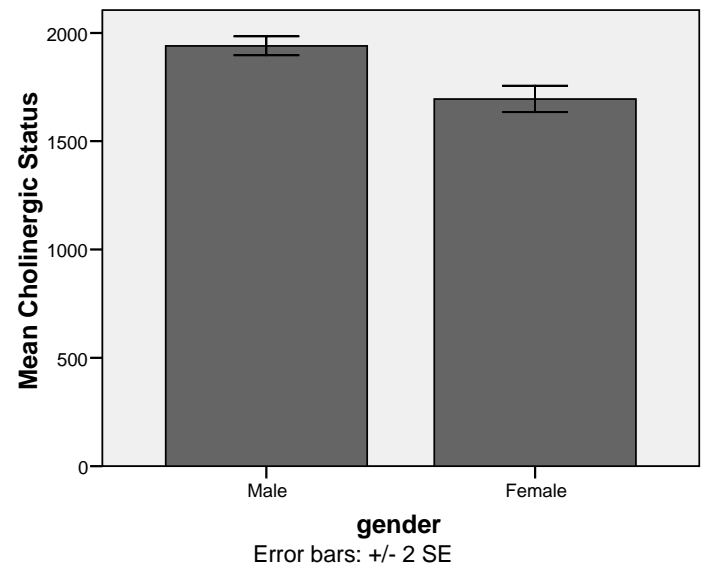

(a)

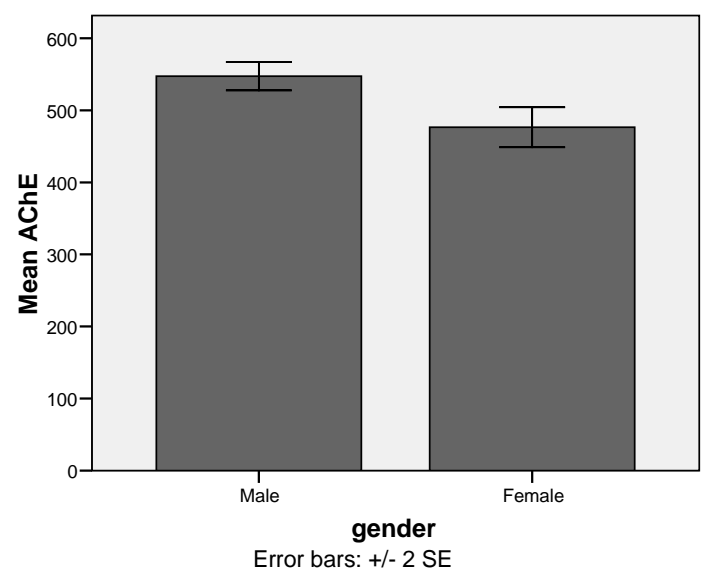

(b)

Figure 1. Association between gender and total cholinesterase activity (a) and AChE activity (b).

senting an obvious gender difference (Figure 1). Tables $\mathbf{3}$ and $\mathbf{4}$ show the Spearman rank correlation coefficient between exercise test variables and serum activity levels of $\mathrm{AChE}$ and BChE. In men favorable HRR parameters and the rate of heart rate increase during exercise (reflected in heart rate peak) were both negatively correlated to $\mathrm{AChE}$ but not $\mathrm{BChE}$ serum activity levels. Resting HR was correlated to AChE in men but not women whereas peak HR was significantly correlated to $\mathrm{AChE}$ in women but not in men. Further, the absolute values of decrease in heart rate 1,2 and 5 minutes following exercise were associated with lower activity levels of AChE. Both men and women showed strong correlations between AChE activities and HR recovery, which were more pronounced in women.

All of the tested subjects were close in their age and mean body mass (Table 1), suggesting that diversities in their serum cholinesterase activity levels reflect physiological, rather than demographic parameters $[32,33]$. 
Table 3. Spearman rank correlation between exercise test variables and total cholinesterase activity in men.

\begin{tabular}{|c|c|c|c|c|}
\hline & \multicolumn{2}{|c|}{$\mathrm{AChE}+\mathrm{BChE}$} & \multicolumn{2}{|l|}{$\mathrm{AChE}$} \\
\hline & $\begin{array}{l}\text { Correlation } \\
\text { coefficient }\end{array}$ & $P$ & $\begin{array}{l}\text { Correlation } \\
\text { coefficient }\end{array}$ & $P$ \\
\hline $\begin{array}{c}\text { Resting heart } \\
\text { rate, (beat/min) }\end{array}$ & 0.102 & 0.100 & 0.210 & $\begin{array}{l}0.0 \\
01\end{array}$ \\
\hline $\begin{array}{l}\text { Heart rate peak, } \\
\text { (beat/min) }\end{array}$ & -0.113 & 0.069 & -0.06 & $\begin{array}{l}0.3 \\
51\end{array}$ \\
\hline $\begin{array}{l}\text { Increase in } \\
\text { heart rate }\end{array}$ & -0.152 & 0.014 & -0.181 & $\begin{array}{l}0.0 \\
05\end{array}$ \\
\hline $\begin{array}{l}\text { Heart rate } \\
\text { recovery } 1 \mathrm{~min} \\
(\text { beat } / \mathrm{min})\end{array}$ & -0.073 & 0.243 & -0.150 & $\begin{array}{l}0.0 \\
22\end{array}$ \\
\hline $\begin{array}{l}\text { Heart rate } \\
\text { recovery } 2 \mathrm{~min} \\
\text { (beat } / \mathrm{min} \text { ) }\end{array}$ & -0.081 & 0.197 & -0.157 & $\begin{array}{l}0.0 \\
16\end{array}$ \\
\hline $\begin{array}{l}\text { Heart rate } \\
\text { recovery } 5 \text { min } \\
\text { (beat } / \mathrm{min} \text { ) }\end{array}$ & -0.141 & 0.026 & -0.176 & $\begin{array}{l}0.0 \\
08\end{array}$ \\
\hline
\end{tabular}

Stratification of subjects according to their measured levels of AChE and total cholinesterase activities into those having above and below mean serum activity levels (Table 5) indicated significant differences. Thus, men who had lower than mean enzyme levels also showed better rates of increase in heart rate as compared with those men who had higher than mean enzyme levels $(\mathrm{p}=$ 0.017 ). This cutoff also extended to HR recovery at 2 and 5 minutes. Women showed a similar dichotomy with re gards to increase in heart rate, but their HR recovery

Table 4. Spearman rank correlation between exercise test variables and total cholinesterase activity in women.

\begin{tabular}{|c|c|c|c|c|}
\hline & \multicolumn{2}{|c|}{$\mathrm{AChE}+\mathrm{BChE}$} & \multicolumn{2}{|c|}{$\mathrm{AChE}$} \\
\hline & $\begin{array}{l}\text { Correlation } \\
\text { coefficient }\end{array}$ & $P$ & $\begin{array}{l}\text { Correlation } \\
\text { coefficient }\end{array}$ & $P$ \\
\hline $\begin{array}{l}\text { Resting heart } \\
\text { rate, (beat/min) }\end{array}$ & 0.065 & 0.447 & 0.07 & 0.431 \\
\hline $\begin{array}{l}\text { Heart rate } \\
\text { peak, } \\
\text { (beat } / \mathrm{min})\end{array}$ & -0.191 & 0.024 & -0.219 & 0.012 \\
\hline $\begin{array}{l}\text { Increase in } \\
\text { heart rate }\end{array}$ & -0.183 & 0.03 & -0.254 & 0.004 \\
\hline $\begin{array}{l}\text { Heart rate } \\
\text { recovery } 1 \mathrm{~min} \\
\text { (beat } / \mathrm{min} \text { ) }\end{array}$ & 0.072 & 0.402 & -0.246 & 0.005 \\
\hline $\begin{array}{l}\text { Heart rate } \\
\text { recovery } 2 \text { min } \\
\text { (beat } / \mathrm{min} \text { ) }\end{array}$ & -0.089 & 0.298 & -0.251 & 0.004 \\
\hline $\begin{array}{l}\text { Heart rate } \\
\text { recovery } 5 \text { min } \\
(\text { beat } / \mathrm{min} \text { ) }\end{array}$ & -0.165 & 0.055 & -0.264 & 0.003 \\
\hline
\end{tabular}

$A C h E$ acetylcholinesterase, $B C h E$ butyrylcholinesterase.
Table 5. Comparison of subjects according to total cholinesterase activity above and below mean serum activity level.

\begin{tabular}{|c|c|c|c|}
\hline 5a. Men & & & \\
\hline & $\begin{array}{l}\mathrm{AChE} \text { and } \mathrm{BChE} \\
\text { Below mean }\end{array}$ & $\begin{array}{c}\text { AChE and } \\
\text { BChE Above } \\
\text { mean }\end{array}$ & $\begin{array}{c}P \\
(t-t e s t)\end{array}$ \\
\hline $\begin{array}{l}\text { Increase in } \\
\text { heart rate }\end{array}$ & $97.6(15.6)$ & $93.2(16.6)$ & 0.017 \\
\hline $\begin{array}{l}\text { Heart rate recov- } \\
\text { ery } 1 \mathrm{~min} \\
\text { (beat } / \mathrm{min} \text { ) }\end{array}$ & $29.7(9.8)$ & $27.8(8.5)$ & 0.105 \\
\hline $\begin{array}{l}\text { Heart rate recov- } \\
\text { ery } 2 \mathrm{~min} \\
\text { (beat } / \mathrm{min} \text { ) }\end{array}$ & $54.8(13.1)$ & $51.4(13.1)$ & 0.039 \\
\hline $\begin{array}{l}\text { Heart rate recov- } \\
\text { ery } 5 \mathrm{~min} \\
\text { (beat } / \mathrm{min} \text { ) }\end{array}$ & $72.8(12.4)$ & $67.7(13.8)$ & 0.002 \\
\hline \multicolumn{4}{|l|}{ 5b. Women } \\
\hline $\begin{array}{l}\text { Increase in } \\
\text { heart rate }\end{array}$ & $91.5(14.2)$ & $86.7(14.3)$ & 0.047 \\
\hline $\begin{array}{l}\text { Heart rate recov- } \\
\text { ery } 1 \mathrm{~min} \\
\text { (beat } / \mathrm{min} \text { ) }\end{array}$ & $31.0(9.2)$ & $30.7(11.2)$ & 0.857 \\
\hline $\begin{array}{l}\text { Heart rate recov- } \\
\text { ery } 2 \mathrm{~min} \\
\text { (beat } / \mathrm{min} \text { ) }\end{array}$ & $61.2(19.6)$ & $57.7(14.1)$ & 0.238 \\
\hline $\begin{array}{l}\text { Heart rate recov- } \\
\text { ery } 5 \mathrm{~min} \\
\text { (beat } / \mathrm{min} \text { ) }\end{array}$ & $75.5(11.5)$ & $72.2(12.6)$ & 0.124 \\
\hline
\end{tabular}

$A C h E$ acetylcholinesterase, $B C h E$ butyrylcholinesterase, Data are presented as mean \pm standard deviation.

values showed no significant correlation to cholinesterase activities. In addition, subjects with heart rate recovery below 20 beats/min had significantly higher AChE + BChE activity levels $(p=0.004)$ and AChE activity level $(\mathrm{p}=0.001)$ compared to subjects with normal heart rate recovery.

\section{Discussion}

Our findings, obtained in a cohort of apparently healthy subjects, suggest that increased total cholinesterase activities as measured in the peripheral blood correlate with increased resting heart rate, attenuated heart rate increase during exercise testing, and delayed heart rate recovery. To the best of our knowledge, the present study is the first to report a readily measurable serum marker for autonomic cardiovascular imbalance.

The link between the autonomic nervous system and cardiovascular mortality has been investigated thoroughly in the last decade, with a multitude of studies indicating a tight association between exercise testing parameters among them resting heart rate, heart rate variability, heart rate recovery after exercise, heart rate increase during exercise and adverse cardiovascular outcome. Abnormalities in these parameters, which are believed to reflect autonomic activity [20], have been shown in diverse 
study populations to be associated with sudden cardiac death in asymptomatic men (resting heart rate and heart rate recovery) [4,21], all cause mortality in cardiac patients (heart rate recovery) [5,22], and all cause mortality and cardiovascular mortality correlated with attenuated heart rate increase [6,23].

These exercise test parameters are postulated to reflect ANS activity consisting mainly of parasympathetic control and to a lesser degree of sympathetic components [20].Specifically, heart rate recovery and heart rate increase during exercise are presumed to be mainly controlled by the parasympathetic branch of the ANS [6] whereas resting heart rate is determined by both sympathetic and parasympathetic activities [24]. Considering that parasympathetic activity is mediated via $\mathrm{ACh}$ release from efferent vagal nerve discharge, we searched for possible associations between the peripheral activity of serum cholinesterases, AChE and BChE and exercise test parameters. Our results clearly demonstrate for both genders that decreased activity of AChE, most likely reflecting increased peripheral ACh levels, was correlated to faster heart rate recovery 1,2 and 5 minutes following cessation of exercise. Additionally, we found that decreased AChE activity was correlated with a rapid heart rate increase in both genders and more profoundly so in women. Two findings which showed genders specifity were that higher than average heart rate peak was correlated to decreased AChE activity in women only and that higher than average resting heart rate was associated with increased AChE activity in men only. Another interesting observation was that using a cut point of 20 beats per minute we were able to stratify subjects into two groups of significantly different AChE activity.

These results are in accordance with previous studies. First, Kakinuma et al. [8] have shown that in a model of acute myocardial ischemia, increasing local ACh secretion in rat cardiomyocytes by electrical stimulation of the vagal efferent nerve decreased infarct size via the PI3K/ Akt/HIF-1alpha pathway. Complementing this study, Ando et al. [9] demonstrated, also in a rat model of myocardial ischemia, that vagal nerve stimulation which elevates release of $\mathrm{ACh}$ exerted antiarrhythmogenic effects accompanied by prevention of the loss of phosphorylated Cx43 during acute myocardial infarction. In line with these data, atria from elderly and diabetic patients were shown to have locally reduced ACh secretion, thus reflecting impaired local parasympathetic activity [25].

Second, previous studies by Katz and coworkers have characterized the systemic effect of AChE inhibition with Pyridostigmine, a short-acting, brain-impenetrable reversible AChE inhibitor which only affects peripheral cholinergic activity. The first study, in chronic heart fail- ure (CHF) patients, showed marked improvement in heart rate recovery [11] and a more recent work showed that Pyridostigmine improved heart rate recovery and resting heart rate in sedentary adults [10].

Strengths of our study include the exclusion of subjects using beta blockers, since the issue of the potential effects of beta blockers on heart rate recovery is still unresolved [29]. Previous studies used statistical adjustment as a means of rectifying this effect, but we chose to remove this possible confounding factor altogether. Additionally, our study population consisted of relatively young subjects without any overt cardiovascular disease thus enabling us to characterize their total cholinesterase activities with less possible confounding factors as would be expected in patients with known cardiovascular disease. Finally, heart rate recovery is a modifiable factor as was previously shown in exercise training of cardiovascular patients $[30,31]$ and with pharmacological therapy with AChE inhibition as noted above.

The limitations of our study involve our ignoring of psychological and/or inflammatory confounding factors; thus, higher than average serum AChE activity may be due to a transient anxiety state [32] or reflect the outcome of infection [12], in which case it would not necessarily predict cardiovascular risk. Additionally, inherited and/or experience-derived changes in the total cholinesterase activities may be caused by polymorphisms in these and/or other genes, e.g. paraoxonase [33] or by altered micro-RNA levels under stress [34,35]. The apparent associations between serum cholinesterase activities and cardiovascular parameters thus merit further in-depth studies.

\section{Conclusions}

Our study links heart rate parameters during exercise testing to a simple, measurable serum marker. We believe that our findings provide important additional insights into the pathophysiology of ANS dysfunction in cardiovascular disease. In view of previous research our findings suggest a possible future avenue for novel therapy modalities of autonomic imbalance. Future studies will be needed to evaluate the added prognostic significance gained by implementing this marker into routine practice.

\section{REFERENCES}

[1] P. J. Schwartz, M. T. La Rovere and E. Vanoli, "Autonomic nervous system and sudden cardiac death. Experimental basis and clinical observations for post-myocardial infarction risk stratification," Circulation, Vol. 85, No. S1, 1992, pp. 77-91.

[2] P. J. Schwartz, "The Autonomic Nervous System and 
Sudden Death," European Heart Journal, Vol. 19, 1998, pp. F72-F80.

[3] M. T. La Rovere, G. D. Pinna, S. H. Hohnloser, F. I. Marcus, A. Mortara, R. Nohara, J. T. Bigger, A. J. Camm and P. J. Schwartz, "Baroreflex Sensitivity and Heart Rate Variability in the Identification of Patients at Risk for Life-Threatening Arrhythmias: Implications for Clinical Trials," Circulation, Vol. 103, No. 16, 2001, pp. 20722077.

[4] X. Jouven, J. P. Empana, P. J. Schwartz, M. Desnos, D. Courbon and P. Ducimetiere, "Heart-Rate Profile during Exercise as a Predictor of Sudden Death," New England Journal of Medicine, Vol. 352, No. 19, 2005, pp. 19511958. doi:10.1056/NEJMoa043012

[5] C. R. Cole, E. H. Blackstone, F. J. Pashkow, C. E. Snader, M. S. Lauer, "Heart-Rate Recovery Immediately after Exercise as a Predictor of Mortality," New England Journal of Medicine, Vol. 341, No. 18, 1999, pp. 1351-1357. doi:10.1056/NEJM199910283411804

[6] N. J. Leeper, F. E. Dewey, E. A. Ashley, M. Sandri, S. Y. Tan, D. Hadley, J. Myers and V. Froelicher, "Prognostic Value of Heart Rate Increase at Onset of Exercise Testing," Circulation, Vol. 115, No. 4, 2007, pp. 468-474. doi:10.1161/CIRCULATIONAHA.106.666388

[7] Y. Loewenstein-Lichtenstein, M. Schwarz, D. Glick, B. Norgaard-Pedersen, H. Zakut and H. Soreq, "Genetic predisposition to adverse consequences of anti-cholinesterases in 'atypical' BCHE carriers," Nature Medicine, Vol. 1, No. 10, 1995, pp. 1082-1085. doi:10.1038/nm1095-1082

[8] Y. Kakinuma, M. Ando, M. Kuwabara, R. G. Katare, K. Okudela, M. Kobayashi and T. Sato, "Acetylcholine from Vagal Stimulation Protects Cardiomyocytes against Ischemia and Hypoxia Involving Additive Non-Hypoxic Induction of Hif-1alpha," FEBS Letters, Vol. 579, No. 10, 2005, pp. 2111-2118. doi:10.1016/i.febslet.2005.02.065

[9] M. Ando, R. G. Katare, Y. Kakinuma, D. Zhang, F. Yamasaki, K. Muramoto and T. Sato, "Efferent Vagal Nerve Stimulation Protects Heart against Ischemia-Induced Arrhythmias by Preserving Connexin43 Protein," Circulation, Vol. 112, No. 2, 2005, pp. 164-170. doi:10.1161/CIRCULATIONAHA.104.525493

[10] T. A. Dewland, A. S. Androne, F. A. Lee, R. J. Lampert and S. D. Katz, "Effect of Acetylcholinesterase Inhibition with Pyridostigmine on Cardiac Parasympathetic Function in Sedentary Adults and Trained Athletes," American Journal of Physiology and Heart Circulation Physiology, Vol. 293, No. 1, 2007, pp. 86-92. doi:10.1152/ajpheart.01339.2006

[11] A. S. Androne, K. Hryniewicz, R. Goldsmith and A. Arwady, S. D. Katz, "Acetylcholinesterase Inhibition with Pyridostigmine Improves Heart Rate Recovery after Maximal Exercise in Patients with Chronic Heart Failure," Heart, Vol. 89, No. 8, 2003, pp. 854-858. doi:10.1136/heart.89.8.854

[12] K. Ofek, K. S. Krabbe, T. Evron, M. Debecco, A. R. Nielsen, H. Brunnsgaad, R. Yirmiya, H. Soreq and B. K. Pedersen, "Cholinergic Status Modulations in Human Volunteers under Acute Inflammation," Journal of Mo- lecular Medicine, Vol. 85, No. 11, 2007, pp. 1239-1251. doi:10.1007/s00109-007-0226-x

[13] A. Steinvil, A. Shirom, S. Melamed, S. Toker, D. Justo, N. Saar, I. Shapira, S. Berliner and O. Rogowski, "Relation of Educational Level to Inflammation-Sensitive Biomarker Level," American Journal of Cardiology, Vol. 102, No. 8, 2008, pp. 1034-1039. doi:10.1016/j.amjcard.2008.05.055

[14] O. Rogowski, S. Toker, I. Shapira, S. Melamed, A. Shirom, D. Zeltser and S. Berliner, "Values of High-Sensitivity C-Reactive Protein in Each Month of the Year in Apparently Healthy Individuals," American Journal of Cardiology, Vol. 95, No. 1, 2005, pp. 152-155. doi:10.1016/j.amjcard.2004.08.086

[15] "Executive Summary of the Third Report of the National Cholesterol Education Program (NCEP) Expert Panel on Detection, Evaluation, and Treatment of High Blood Cholesterol in Adults (Adult Treatment Panel III)," JAMA, Vol. 285, No. 19, 2001, pp. 2486-2497.

[16] P. M. Rautaharju, R. J. Prineas, W. J. Eifler, C. D. Furberg, J. D. Neaton, R. S. Crow, J. Stamler and J. A. Cutler, "Prognostic Value of Exercise Electrocardiogram in Men at High Risk of Future Coronary Heart Disease: Multiple Risk Factor Intervention Trial Experience," Journal of the American College of Cardiology, Vol. 8, No. 1, 1986, pp. 1-10. doi:10.1016/S0735-1097(86)80084-5

[17] ACSM's Metabolic Calculations Handbook, Philadelphia, Lippincott Williams \& Wilkins, PA, 2006.

[18] A. Berson, M. Knobloch, M. Hanan, S. Diamant, M. Sharoni, D. Schuppli, B. C. Geyer, R. Ravid, T. S. Mor, R. M. Nitsch and H. Soreq, "Changes in Readthrough Acetylcholinesterase Expression Modulate Amyloid-Beta Pathology," Brain, Vol. 131, No. Pt1, 2008, pp. 109-119.

[19] A. Gilboa-Geffen, P. P. Lacoste, L. Soreq, G. Cizeron-Clairac, R. Le Panse, F. Truffault, I. Shaked, H. Soreq and S. Berrih-Aknin, "The Thymic Theme of Acetylcholinesterase Splice Variants in Myasthenia Gravis," Blood, Vol. 109, No. 10, 2007, pp. 4383-4391. doi:10.1182/blood-2006-07-033373

[20] M. K. Lahiri, P. J. Kannankeril, J. J. Goldberger, "Assessment of Autonomic Function in Cardiovascular Disease: Physiological Basis and Prognostic Implications," Journal of the American College of Cardiology, Vol. 51, No. 18,2008 , pp. 1725-1733. doi:10.1016/j.jacc.2008.01.038

[21] Adabag AS, Grandits GA, Prineas RJ, Crow RS, Bloomfield HE, Neaton JD. Relation of heart rate parameters during exercise test to sudden death and all-cause mortality in asymptomatic men. American Journal of Cardiology $2008 ; 101(10): 1437-1443$. doi:10.1016/j.amjcard.2008.01.021

[22] R. Arena, M. Guazzi, J. Myers and M. A. Peberdy, "Prognostic Value of Heart Rate Recovery in Patients with Heart Failure," American Heart Journal, Vol. 151, No. 4, 2006, pp. 851-857. doi:10.1016/j.ahj.2005.09.012

[23] K. P. Savonen, V. Kiviniemi, J. A. Laukkanen, T. A. Lakka, T. H. Rauramaa, J. T. Salonen and R. Rauramaa, 
"Chronotropic Incompetence and Mortality in Middle-Aged Men with Known or Suspected Coronary Heart Disease," European Heart Journal, Vol. 29, No. 15, 2008, pp. 1896-1902. doi:10.1093/eurheartj/ehn269

[24] D. Robertson, G. A. Johnson, R. M. Robertson, A. S. Nies, D. G. Shand and J. A. Oates, "Comparative Assessment of Stimuli That Release Neuronal and Adrenomedullary Catecholamines in Man," Circulation, Vol. 59, No. 4, 1979, pp. 637-643.

[25] V. Oberhauser, E. Schwertfeger, T. Rutz, F. Beyersdorf and L. C. Rump, "Acetylcholine Release in Human Heart Atrium: Influence of Muscarinic Autoreceptors, Diabetes, and Age," Circulation, Vol. 103, No. 12, 2001, pp. 1638-1643.

[26] D. P. Vivekananthan, E. H. Blackstone, C. E. Pothier and M. S. Lauer, "Heart Rate Recovery after Exercise is a Predictor of Mortality, Independent of the Angiographic Severity of Coronary Disease," Journal of the American College of Cardiology, Vol. 42, No. 5, 2003, pp. 831-838. doi:10.1016/S0735-1097(03)00833-7

[27] B. Aijaz, R. W. Squires, R. J. Thomas, B. D. Johnson and T. G. Allison, "Predictive Value of Heart Rate Recovery and Peak Oxygen Consumption for Long-Term Mortality in Patients with Coronary Heart Disease," American Journal of Cardiology, Vol. 103, No. 12, 2009, pp. 1641-1646. doi:10.1016/j.amjcard.2009.02.013

[28] L. R. Davrath, S. Akselrod, I. Pinhas, E. Toledo, A. Beck, D. Elian and M. Scheinowitz, "Evaluation of Autonomic Function Underlying Slow Postexercise Heart Rate Recovery," Medical Science Sports Exercise, Vol. 38, No. 12, 2006, pp. 2095-2101. doi:10.1249/01.mss.0000235360.24308.c7

[29] A. P. Morise, "Heart Rate Recovery: Predictor of Risk Today and Target of Therapy Tomorrow?" Circulation, Vol. 110, No. 18, 2004, pp. 2778-2780. doi:10.1161/01.CIR.0000147615.62634.48

[30] P. Kligfield, A. McCormick, A. Chai, A. Jacobson, P.
Feuerstadt and S. C. Hao, "Effect of Age and Gender on Heart Rate Recovery after Submaximal Exercise during Cardiac Rehabilitation in Patients with Angina Pectoris, Recent Acute Myocardial Infarction, or Coronary Bypass Surgery," American Journal of Cardiology, Vol. 92, No. 5, 2003, pp. 600-603. doi:10.1016/S0002-9149(03)00733-1

[31] J. Myers, D. Hadley, U. Oswald, K. Bruner, W. Kottman, L. Hsu and P. Dubach, "Effects of Exercise Training on Heart Rate Recovery in Patients with Chronic Heart Failure," American Heart Journal, Vol. 153, No. 6, 2007, pp. 1056-1063. doi:10.1016/j.ahj.2007.02.038

[32] E. H. Sklan, A. Lowenthal, M. Korner, Y. Ritov, D. M. Landers, T. Rankinen, C. Bouchard, A. S. Leon, T. Rice, D. C. Rao, J. H. Wilmore, J. S. Skinner and H. Soreq, "Acetylcholinesterase/Paraoxonase Genotype and Expression Predict Anxiety Scores in Health, Risk Factors, Exercise Training, and Genetics Study," Proceedings of the National Academy of Sciences USA, Vol. 101, No. 15, 2004, pp. 5512-5517. doi:10.1073/pnas.0307659101

[33] B. Bryk, L. BenMoyal-Segal, E. Podoly, O. Livnah, A. Eisenkraft, S. Luria, A. Cohen, Y. Yehezkelli, A. Hourvitz and H. Soreq, "Inherited and Acquired Interactions between Ache and Pon1 Polymorphisms Modulate Plasma Acetylcholinesterase and Paraoxonase Activities," Journal of Neurochemistry, Vol. 92, No. 5, 2005, pp. 1216-1227. doi:10.1111/j.1471-4159.2004.02959.x

[34] C. Guimaraes-Sternberg, A. Meerson, I. Shaked and H. Soreq, "MicroRNA Modulation of Megakaryoblast Fate Involves Cholinergic Signaling," Leukocyte Research, Vol. 30, No. 5, 2006, pp. 583-595. doi:10.1016/j.leukres.2005.09.005

[35] I. Shaked, A. Meerson, Y. Wolf, R. Avni, D. Greenberg, A. Gilboa-Geffen and H. Soreq, "MicroRNA-132 Potentiates Cholinergic Anti-Inflammatory Signaling by Targeting Acetylcholinesterase," Immunity, Vol. 31, No. 6, 2010, pp. 965-73. doi:10.1016/j.immuni.2009.09.019 